\title{
Dementia cafés: Recommendations from interviews with informal carers
}

\begin{tabular}{|r|l|}
\hline Journal: & Working with Older People \\
\hline Manuscript ID & WWOP-07-2017-0018 \\
\hline Manuscript Type: & Research Paper \\
\hline Keywords: & Dementia Café; , Alzheimer's Café, carer;, care giver, experience, support \\
\hline \multicolumn{2}{|l}{} \\
\hline
\end{tabular}

\section{SCHOLARONE"}

Manuscripts 


\title{
Dementia cafés: Recommendations from interviews with informal carers
}

\begin{abstract}
Dementia cafés (also known as Alzheimer's or memory cafés) have been running in the United Kingdom (UK) since 2000. This article reports on the recommendations from recent research that interviewed family carers on their experiences of using the cafés. The research was carried out in cafés in and around London, and focussed on informal, unpaid carers' experiences of using them. Eleven carers from five different dementia cafés were interviewed, using semi structured questionnaires. The results were thematically analysed. The findings showed that carers had an overwhelming appreciation of the cafés and what they offered, but several of the findings led to the recommendations about the recruitment and training of café coordinators; how cafés present themselves and their services and how they can offer dedicated support to informal carers. These recommendations will be of use to café organisers and commissioners, especially considering the dearth of information currently available in this area.
\end{abstract}

\section{Keywords:}

Dementia Café; Alzheimer's Café; carer; care giver; experience; support.

\section{Background}

Worldwide, increasing numbers of people are living with dementia. In the United Kingdom (UK) in 2013, approximately 816,000 people were living with dementia, (Prince et al. 2014). Numbers are expected to rise to over one million by 2025 (Lewis et al. 2014). There are similar trends internationally. Prince et al, (2015) suggest that if Dementia were a country, it would be the 18th largest economy in the world. Most people with dementia live in the community supported by informal or family carers (Schulz \& Martire 2004). As populations age, numbers of these informal carers are also increasing. In the UK, the number of carers of people living with dementia was estimated at 670,000 in 2014 (Prince et al -2014) and is expected to rise to 1.7 million by 2050 (Lewis et al. 2014).

Living with dementia can be challenging for both the person with the diagnosis and their loved ones (Schoenkmakers et al. 2010; Schulz \& Sherwood 2009. Carers report, for example, reduced quality of life (Hurt et al. 2008) and poorer mental and physical health (Argimon et al. 2004). Added to this people with dementia and their carers report both reduced social support (Stoltz et al. 2004) and even stigma related to the condition (Daly et al. 2013). 
Given these challenges and the important role informal carers play in supporting their loved ones to continue to live in the community, carers of people living with dementia deserve and need support with their role. In the UK, support services for people living with dementia and their family carers have been highlighted as a priority for development by the government (Department of Health [DH] 2009; DH 2016). There are a variety of well-established supportive community services, including: one-to-one peer support (Greenwood et al. 2013; Smith \& Greenwood, 2014), befriending (Charlesworth et al. 2008), support groups (Dam et al. 2017) and singing, music and art groups (Camic et al. 2011; Rusted et al. 2006; Sherratt et al. 2004).

\section{Dementia cafés}

Dementia cafés (also known as Alzheimer's or memory cafés) are a relatively recent development. They were first developed in the Netherlands by Dr. Bere Miesen and introduced in the UK in 2000 (Miesen \& Jones 2004). A key concept behind the model is one of encouraging people with dementia and their families to continue living as normal a life as possible. The cafés provide an opportunity to connect with peers, (thereby encouraging self-help and informal support) as well as providing information and formal support (Droes et al. 2004).

Cafés are usually run in the third sector and often meet monthly for about two hours at a regular venue e.g. a library or church hall. The degree to which these sessions are structured can vary, but there is usually an opportunity for informal socialisation, and some kind of structured, facilitated activity (such as singing or crafts) (Droes et al. 2004). Sessions are also a source of useful information on topics such as the causes and symptoms of dementia, and the different services available.

This article describes recommendations based on our qualitative study about carers' experiences of attending dementia cafés (Greenwood et al. 2017). Some are recommendations for change made by the carers themselves but others reflect what the carers described as working well and should therefore continue.

\section{The study}

The research was carried out in dementia cafés in and around London, England, and focussed on informal, unpaid carers' experiences of attending them. Potential dementia cafés were contacted through the café managers. Where we were given permission, we visited the café to recruit carers. Eligible participants needed to have attended a café at least three times in the last six months (to ensure that they were regular attenders and would have had sufficient experiences with the cafés to be comfortable talking about them). Eleven carers from five different dementia cafés were interviewed, using recorded semi-structured interviews. We used a topic guide to ensure that the interviews included what they enjoyed and what they liked less about the cafés. Ethical approval for the study was given by the Faculty of Health, Social Care and Education Research Ethics Committee, Kingston University and St 
George's University of London. The carers were mostly spouses. Eight were women and three were men. They were all aged over 40 years and most of them were over 60 years. Carers described their experiences in some detail and had an overwhelming appreciation of the cafés and what they offered, but several of the findings led to the following recommendations.

\section{Recommendation 1: The recruitment and training of café Co-ordinators}

Café co-ordinators played an important part in carers' experiences and were frequently praised for their positive personal qualities. Co-ordinators welcomed newcomers, and enabled people to "feel at ease", and "have a laugh" with them. As one carer commented:

“...they're very nice people...their hearts in the right place and they, you know, are very accommodating on the whole... I mean, I was worried about another carer for example and I rang her [café co-ordinator] up and I feel that I can do that sort of thing."

Co-ordinators were frequently described as approachable, often being seen as the first port of call.

"I mean I get on very well with [Café Co-ordinator] and having only seen her about four times, you know, I find very, she's a very easy person and she's very helpful, if you ask for information and she hasn't got it to hand she will take a note and you know and find out for you, yeah which I think is very helpful."

One participant was moved when a newly arrived café organiser was one of the few people to attend his wife's funeral.

“...when it came to (my wife's) funeral I sent out invitations, and the word had got back from the Alzheimer's Association. They wrote to me and said they sent their condolences. They knew me well. And the lady rang up, "When is the funeral?" She was the only one, l'd only met her once and yet she came to the funeral. Several people l've known for ages didn't come and that touched me..."

Café Co-ordinators offered a personalised, individual and caring service. They were praised for being open and accepting of people with dementia and their carers.

This suggests care should be taken in the selection and training of staff for this role. Recruiting and developing capability to respond to the needs of people and their carers can be a challenging process. Sheard (2013) argues that emotional intelligence should be a pre-requisite before attempting to develop the right set of skills, he discusses the need for 'attached professionalism' to be found in dementia 
care (a quality that was observed with many of the co-ordinators and café workers in this study).

\section{Recommendation 2: The importance of being presented as 'cafés'}

Being described as 'cafés' was important. Cafés are somewhere where you can socialise and enjoy refreshments and similarly these dementia cafés were seen as sustaining places, emotionally, and with an appreciation of the food and hospitality offered. As one carer commented, it only costs

"two pounds to attend... but she can have as many cups of tea, and if she wants juice, she can have juice, she can have her cake, she'll have sandwiches, you know, they put on a nice, a nice little spread for them as well, and I think the way they put the spread out always is inviting to people..."

The café style set up with tables, snacks and drinks perhaps creates an atmosphere where people can relax and socialise as they might if it was not a 'dementia' cafe.

"Being in there, some nice food, talking to people and looking round and thinking who is doing what, um and I become the part of the group, I'm not kind of carer sitting in the corner, I'm just become part of the whole thing, that is quite interesting."

Whilst re-affirming the importance of the café style for those setting up cafés, it is also important to acknowledge how the provision of low cost refreshments contributed to creating this sustaining environment.

\section{Recommendation 3 Reviewing how cafés are publicised}

Carers valued the unique services of the café but a few commented on the sporadic and low attendance at some of them.

Two of the five cafes were held in large rooms at local health centres and a third was run in a day centre for older people. They were in accessible locations where a health or social care service had offered an appropriate space for the session. Carers often found out about the cafés through clinicians when the diagnosis of dementia had been made.

Dementia café organisers may therefore wish to review how they disseminate information about their services, and ensure that this is across the whole range of professionals working with dementia, especially highlighting their usefulness shortly after diagnosis. 


\section{Recommendation 4: Be clear of the purpose and rationale of activities and keep them appropriately updated}

Cafés provided a wide range of activities that were in general, well received/ welcomed by carers and people living with dementia. However, it may be helpful for café organisers to consider the purpose and rationale of these activities. Not all carers interviewed could see their immediate relevance. It is also important that the activities provided are suitable for people with dementia and their carers.

For example, one daughter noted that her mother (person with dementia) lacked interest in some activities possibly because they did not encourage interaction with others:

"...definitely less interested in activities that, that you normally do on your own, like kind of craft things or art things or um they're a little bit more internally focussed. I mean I guess they include those things because they're aware that people may have done those as hobbies and feel comfortable doing them, so I kind of get that. Um but they don't always lend themselves to conversation ..."

Another carer commented that there were times when activities could be inappropriate for the café attendees:

"A young girl came in with a machine, she said '...We'll do exercises but they'll be gentle'. Gentle?! We come out of there it nearly killed us, we were up down up down, you ask anyone about Zuba [sic] dance, they'll tell you..."

One specific activity - singing - was referred to repeatedly. It was noted that songs continued to centre around the 1940's. There was enjoyment and nostalgia about these, as one carer noted.

"It makes you feel part of history, so that's again another positive in the memory café, because the activities that they put on, are just great"

However, another commented that war songs were "old when I was young" and saw them as outdated and patronising:

“... (war songs) belittle elderly people and think all they want is songs going back so far, like the old music hall, you know, because when you think about it, well we'll say a seventy year old, I suppose that's the average right, I'm a bit older but the average. Now seventy, I mean they can remember the Beatles, they were teenagers when the, if you go back to the sixties and seventies, that's fifty years ago, but everybody knows the Beatles..."

Carers may not feel confident enough to challenge café organisers or to ask them about the rationale behind the activities offered. So it may be helpful for café organisers to be more explicit about the aims and objectives of activities perhaps 
with a written statement available that makes this clear to carers, and to regularly ask for feedback from carers.

\section{Recommendation 5: Review how information is presented}

Cafés offered a lot of practical information to people with dementia and their carers. This included printed information signposting them to other services, or informing them of services that were accessible for people with dementia.

At times, the amount of information being provided was seen as too much. Also, it was not always clear to carers, why the information was being provided or what they should do with it:

"Some of the information and I guess it's more relevant for carers and it's directed at the people themselves but, I mean I know my mum's not going to remember a thing so it's kind of pointless um and they don't um yeah, so they don't deliver the information very effectively..."

"There's never any follow up as to how the information's been used so you kind of wonder you know, well what was the point of that really?"

Specific directions as to how to use the information would be helpful, signposting its relevance:

“... even something like an instruction on the top saying 'Put this by your telephone' so that they know what to do with it when they get home or 'put this up in your kitchen'. You know something like that or 'give this to your primary carer.",

Another suggestion was for 'taster sessions' by visiting service providers:

"I wonder whether you know, they should actually offer to come along to memory café and do like a free five minute consultation or like a free five minute chat so you can experience a little bit of the service and then you might actually access it, um but I can see, so I know this is the way I feel and I can see it on other people's faces when they get told about the service and they get handed a leaflet and they go 'Oh OK', you know it gets put in the bag and you know they'll not do anything about it because you get home and then you think, 'Nah I won't bother, it's not for people like me'

Café organisers may therefore wish to review their strategy for presenting information, bearing in mind that this can sometimes be perceived as overwhelming to carers.

\section{Recommendation 6: Having a dedicated space for carers}

For some carers, it was important to spend the time in the café with the person they cared for, as a shared experience: 
“...An experience that we've done together, which is also important, so I wouldn't give that up lightly."

However, there was also the need for some space alone, with other carers, to share things that they could not around the person they cared for. This allowed them to speak openly about the challenges they faced and to seek out peer support. One carer felt that some dedicated space, just for carers "would go down well for me". Another noted that

"I think emotionally it's much better like, it's not a one to one basis but you've got other people that share...Whilst you've got a person with dementia there and it's not everything you want to say."

If they are not already doing so, cafés might consider offering carers a group or activities just for carers, as well as activities for everyone, thus providing time together and time apart.

\section{Recommendation 7: Frequency of opening}

Most participants valued their time at the café and felt that meeting once a month was not enough

"Well, I think what I would like, I think I would prefer it if the memory cafes could be, I wonder perhaps more days or you know, I mean there was somebody I was talking to and I think they have a memory café every day or something or you know."

Other carers preferred fortnightly meetings, although, for working carers, this also presented difficult choices around what they would then need to give up in order to attend.

"I would like my mum to go more often. Um so I would be keen for her to go if it was fortnightly, but then it's whether I could make that happen."

\section{Conclusion}

Dementia cafés offer an important sense of place to carers and people with dementia. They provide information, support and emotional sustenance that carers identified as being unique. This seems especially important following the dementia diagnosis . However, some carers questioned the purpose of and rationale for the activities offered, as well as the need to provide the amount of information that, at times, felt overwhelming. Many requested that the cafés were held more frequently, and some asked for a specific space for carers.

Most carers spoke about the cafés with fondness, and their impact can perhaps be summed up by this carer. 
"The memory café has been the one constant thing. So all the other activities that we've done, they kind of come and go, or they're seasonal or whatever, but the memory café, I quite like the consistency, the fact that it's every month all throughout the year over a period of years, so yeah I think that's a benefit."

\section{References}

Argimon, J.M., Limon, E., Vila, J., Cabezas, C.(2004) Health-related quality of life in carers of patients with dementia. Family Practice 2004. 21 (4): 454-457.

DOI:https://doi.org/10.1093/fampra/cmh418

Camic PM, Myferi C, Meeten F. (2011) Does a 'Singing Together Group' improve the quality of life of people with a dementia and their carers? A pilot evaluation study. Dementia: The International Journal of Social Research \& Practice, 12(2), 157-176.

Charlesworth, G., Shepstone, L., Wilson, E., Thalanany, M., Mugford, M. \& Poland, F. (2008). Does befriending by trained lay workers improve psychological well-being and quality of life for carers of people with dementia, and at what cost? A randomised controlled trial. Health Technology Assessment (Winchester, England), 12(4), v.

Daly L, McCarron M, Higgins A, McCallion P. 'Sustaining Place' - a grounded theory of how informal carers of people with dementia manage alterations to relationships within their social worlds. Journal of Clinical Nursing. 2013;22(3-4):501-512.

Dam AE, de Vugt ME, Klinkenberg IP, Verhey FR, van Boxtel MP. A systematic review of social support interventions for caregivers of people with dementia: Are they doing what they promise? Maturitas. 2016;85:117-130.

Department of Health. (2009). Living well with dementia: A National Dementia Strategy. London: Crown.

Department of Health. (2016) Prime Minister's Challenge on Dementia 2020. London: Department of Health.

Droes R.M., Goffin J.J.M., Breebart, E., de Rooij, E., Vissers,H., Bleeker, J.A.C., van Tilburg W. "Support programmes for caregivers of persons with dementia: a review of methods and effects" In Jones, GMM and Miesen BML (2004) Care giving in dementia: research and applications, Volume 3. Brunner-Routledge. New York, USA.

Greenwood, N., Habibi, R., Mackenzie, A., Drennan, V. \& Easton, N. (2013). Peer support for carers: A qualitative investigation of the experiences of carers and peer 
volunteers. American Journal of Alzheimer's Disease and Other Dementias, 28(6), 617-626.

Greenwood N, Smith R, Akhtar F, Richardson A (2017) A qualitative study of carers' experiences of dementia cafés: a place to feel supported and be yourself. Bio Medical Central Geriatrics 17:164

Hurt C., Bhattacharyya S., Burns A., Camus, V., Liperoti R., Marriott A., Nobili F., Robert P., Tsolaki M., Vellas B., Verhey F., and Byrne E. (2008) Patient and Caregiver Perspectives of Quality of Life in Dementia: An Investigation of the Relationship to Behavioural and Psychological Symptoms in Dementia. Dementia and Geriatric Cognitive Disorders. 2008;26:138-146. doi.org/10.1159/000149584

Lewis, F., Schaffer, S.K., Sussex, J., O’Neill, P. \& Cockcroft, L. (2014). The trajectory of dementia in the UK - making a difference. Consulting Report. London: Office of Health Economics.

Miesen, B. L., \& Jones, G. M. M. (2004) The Alzheimer café concept: A response to the trauma, drama and tragedy of dementia. In Jones, G. M. M. \& Miesen, B.L. (Eds.), Care giving in dementia: Research and applications (Vol. 3; 307-333). Hove: Brunner Routledge.

Prince, M., Knapp, M., Guerchet., M, McCrone. P., Prina, M., Comas-Herrera, A., Wittenberg, R., Adelaja, B., Hu, B., King, D., Rehill, A and Salimkumar, D (2014) Dementia UK: Update. Second edition. Alzheimers' Society. https://www.alzheimers.org.uk/download/downloads/id/2323/dementia uk update.pd f

Prince, M., Wimo, A., Guerchet, M., Ali, G.C.,Wu, Y.T., Prina, M. (2015) World Alzheimer Report 2015: The Global Impact of Dementia: an analysis of prevalence, incidence, cost and trends. Alzheimers Disease International available online at https://www.alz.co.uk/research/WorldAlzheimerReport2015.pdf

Rusted J, Sheppard L, Waller D.E. (2006) A multi-centre randomized control group trial on the use of art therapy for older people with dementia. Group Analysis, 39(4), 517-536.

Schoenmakers B, Buntinx F, DeLepeleire J (2010) Supporting the dementia family caregiver: the effect of home care intervention on general well-being. Aging and Mental Health 14(1):44-56.

Schulz R, Martire LM. (2004) Family caregiving of persons with dementia: prevalence, health effects, and support strategies 2004;12(3):240-249.

Schulz, R. \& Sherwood, P.R. (2009). Physical and mental health effects of family caregiving. American Journal of Nursing, 108(9), 23-27. 
Sheard, D (2013) The feeling of 'mattering': the positioning of emotions in dementia care. The Journal of Dementia Care Vol 21 (2) pp 23-27

Sherratt, K, Thornton, A \& Hatton, C (2004) 'Music interventions for people with dementia: a review of the literature'. Aging and Mental Health, vol 8, no. 1, pp. 312.

Smith, R \& Greenwood, N. (2014). The impact of volunteer mentoring schemes on carers of people with dementia and volunteer mentors: A systematic review.

American Journal of Alzheimer's Disease and Other Dementias, 29(1), 8-17.

Stoltz P, Udén G, Willman A. (2004) Support for family carers who care for an elderly person at home - a systematic literature review. Scandinavian Journal of Caring Sciences. 2004 18(2):111-119. 